
\title{
R Research Soure \\ Research on Eco-Efficiency of 11 Cities in Zhejiang Province: Based on the Perspective of High Quality Development
}

$\mathrm{Xu} \mathbf{X u}$

Wenzhou University

Lizhen Huang (D 184511082134@stu.wzu.edu.cn )

Taizhou University https://orcid.org/0000-0003-1126-4258

\section{Research Article}

Keywords: Zhejiang Province, Eco-efficiency, Super-SBM, Malmquist index, Tobit

Posted Date: December 14th, 2021

DOI: https://doi.org/10.21203/rs.3.rs-1082301/v1

License: (c) (1) This work is licensed under a Creative Commons Attribution 4.0 International License.

Read Full License 


\title{
Research on Eco-Efficiency of 11 Cities in Zhejiang Province: Based on the Perspective of High Qual- ity Development
}

\author{
$\mathrm{Xu} \mathrm{Xu^{1 }}$. Li-zhen Huang ${ }^{2 *}$.
}

\begin{abstract}
Ecological efficiency (Eco-efficiency) index well represents the quality of regional development and measures the extensive or intensive development mode of a region. The traditional concept of Eco-efficiency refers to the maximum economic benefits through the minimum resource cost and environmental load. This paper argues that the goal of Eco-efficiency evaluation is not only to maximize economic benefits, but also to achieve high-quality development in many aspects such as society, science \& technology and economy, so that people can enjoy the results of development.

In this paper, the Eco-efficiency input indicators comprehensively considers the consumption of manpower, resources, energy and capital, and negative environmental benefits including waste gas, waste water and waste residue. Output indicators comprehensively consider the five high-quality development dimensions----innovation, coordination, green, openness and sharing, which are represented by indicators such as patents, total import and export, the number of patent, regional Theil index, disposable income, three waste emissions et al. .

In terms of empirical research, the SBM model of undesirable output super-efficiency under the assumption of variable returns to scale is established to measure the Eco-efficiencies of 11 cities in Zhejiang Province. Secondly, Malmquist index model is estalished to study the temporal and spatial changes of Eco-efficiencies. Finally, the panel Tobit method is used for regression analysis to study the key factors affecting the Eco-efficiency of Zhejiang Province. The results show that the industrialization structure, economic level and export trade significantly positively correlated with Eco-efficiency. Urbanization level is significantly negatively correlated with Eco-efficiency.
\end{abstract}

Keywords: Zhejiang Province. Eco-efficiency. Super-SBM. Malmquist index. Tobit

\section{Introduction}

Eco-efficiency initially refers to ' the actual utilization of energy between the various nutritional levels of the food chain accounted for the percentage of available energy '. With the development of the world economy, after the seventies and eighties of the twentieth century, some developed countries gradually attached importance to environmental protection in the development of economic and environmental strategies, and this concept gradually attracted wide attention of scholars from all walks of life.

The World Business Council for Sustainable Development (WBCSD) defines it as: 'Eco-efficiency is achieved by providing products or services that can meet human needs and ensure the quality of life, while reducing the ecological impact and resource intensity of the entire life cycle to the level that the earth can withstand. Specifically, the process of improving Eco-efficiency requires the use of resources, economic development, scientific and technological development to maximize human needs and the quality of life. In contrast, resource consumption and waste pollution need to be minimized. The Organization for Economic Co-operation and Development (OECD) believes that Eco-efficiency is the efficiency of the use of ecological resources that meets human needs' and can be seen as a ratio of output to input. In the new era, China's economy has shifted from a high-speed growth stage to a high-quality development stage. The output system of Eco-efficiency is no longer just considered from the total amount of the economy, but should make innovation, coordination, green, openness and sharing move towards high-quality development.

Zhejiang Province is located in the southeast coast of China, its east is close to the East China Sea, and its north is close to Shanghai and Jiangsu. In 2020, Zhejiang Province, with an area of 10.56 million square kilometers and only 1.10 percent of the country 's land, is one of the smallest provinces in China, but its GDP ranks fourth in China. By 2020, per capital disposable income ranked the top three in China, after Shanghai and Beijing. Zhejiang Province has 11 cities, including Hangzhou, Ningbo, Wenzhou, Shaoxing, Huzhou, Jiaxing, Jinhua, Quzhou, Zhoushan, Taizhou and Lishui. Zhejiang is

\section{Email: Xu Xu : xuxu@wzu.edu.cn}

Li-zhen Huang : 184511082134@stu.wzu.edu.cn

School of Mathematics and Physics, Wenzhou University, Zhejiang, P.R. China.

School of Mathematics and Physics, Wenzhou University, Zhejiang, P.R. China. 
also one of the most active provinces in China. It has unique advantages in business and investment environment, urban construction and natural environment, and has formed a distinctive feature of 'Zhejiang economy'. Compared with the political center Beijing and China's financial city Shanghai, Zhejiang Province is more representative in the development model of China's provinces. Through the research on the Eco-efficiency of Zhejiang Province, it has demonstration and enlightenment for the improvement of Eco-efficiency in other provinces.

This paper regards ' Eco-efficiency ' as one of the leading indicators of 'high quality development' and expands the connotation of 'Eco-efficiency' to adapt to China's national conditions. Firstly, the super-SBM model with unexpected output and variable returns to scale is established, which is of practical significance to measure the Eco-efficiency of 11 cities in Zhejiang Province. Secondly, this paper uses Malmquist index model to study the temporal and spatial variation of Eco-efficiency, which can capture the dynamic relationship between economic development and ecological protection in Zhejiang Province. Finally, the panel Tobit method is used to study the key factors affecting the Eco-efficiency. The results can provide an effective way to improve the Eco-efficiency.

\section{Literature Review}

\section{The Concept of Eco-efficiency}

Ecological efficiency is referred to as Eco-efficiency, the root of the word ' Eco ' is characterized by ' economic ' and ' ecological ' two dimensions, indicating that the concept of ecological efficiency needs to examine both economic and ecological efficiency.

The concept of eco-efficiency was first used by the Canadian Scientific Committee in the 1970s and was reiterated by the World Union for Conservation of Natural Resources in the 1980s, but the two did not give a clear definition of the concept of eco-efficiency. Schaltegger and Sturm (1990) first proposed the concept of eco-efficiency and gave a clear definition of the ratio of increased value to increased environmental loads. In 1992, the World Business Council for Sustainable Development ( WBCSD ) first cited the concept of ecological efficiency in economic activities from an economic perspective. In summary, Scholars and organizations defined Eco-efficiency mainly as the ratio of input to output, with the main objectives of minimizing resource input, minimizing environmental pollution and maximizing economic output.

Fuss et al. (1995) introduced the concept of ecological efficiency into China for the first time, and Li et al. (2008) cited the concept of Eco-efficiency when discussing environmental policies and management-related issues in China. Zhou et al. (2014) considered that Eco-efficiency can be measured by the ratio of input to output, which is the efficiency of ecological resources in meeting human needs. Tang et al. (2012) proposed that ecological efficiency can gradually reduce its ecological impact and resource intensity when providing quality products and services. Chu et al. (2010) and Qiu et al. (2012) believed that Eco-efficiency was the ratio of the realized economic value to the corresponding resource and environment consumption. Wang et al. (2013) summarized the Eco-efficiency as: maximizing the value while minimizing resource consumption, pollution and waste emissions. Subsequently, scholars elaborated and studied the nature and application of ecological efficiency (Lv et al., 2011; Gan et al., 2013; Liu et al., 2017; Zhang et al., 2016 ). Eco-efficiency is the ratio of social services to the growth rate of ecological load, a dimensionless expression, similar to the reciprocal of elastic coefficient (Huang et al.,2017).

In general, scholars in China and abroad have a consistent view on Eco-efficiency. They believed that Eco-efficiency considers both environment and resources and economic value, which is a kind of multiple double consideration. Its fundamental purpose was to exchange the minimum resources and environmental inputs for more economic value.

\section{Quantitative Analysis Method of Eco-efficiency}

WBCSD was the first to quantify the concept of Eco-efficiency. Since then, various quantitative research methods have gradually developed. In terms of the quantitative measurement methods of Eco-efficiency, there are measurement methods according to different evaluation scales and purposes. At present, the Eco-efficiency calculation methods include Ratio Method, Synthetical Index Method, Data Envelopment Analysis (DEA), Substance Flow Analysis (SFA) and Energy Analysis. Ratio method is used to solve the ratio between selected socio-economic indicators and environmental indicators (Huang et al., 2010) Synthetical Index Method assigns weights to the indicators set through principal component analysis, factor analysis or entropy weight method, and then calculates the Eco-efficiency (Yang \& Du, 2017; Liang \& Zhuo, 2017).SFA is an analytical tool to quantify the flow of specific substances in a specific system in a certain space-time range ( $\mathrm{Gu} \& \mathrm{Liu}, 2017$ ). Based on the flow of material energy, Energy method effectively combines system ecology and Eco-economics to analyze the Eco-efficiency of regional economy (Huang \& Wang, 2015).

At present, the most commonly used method is Data Envelopment Analysis ( DEA ). The main advantage of the DEA series model is that it overcomes the subjective weighting problem existing in the single ratio method. By putting the input and output indicators of different units in the same analytical framework, the weight of the indicators is objectively calculated according to the data, and thus it is widely used.( Kuosmanen \& Kortelainen, 2005 . Picazo-Tadeo et al., 2012. Rebolledo-Leiva et al., 2017. Huang et al., 2014 ).

The traditional DEA method has the efficiency value of 1 
for multiple Decision Making Units (DMUs), which cannot effectively distinguish the advantages and disadvantages of DMU. The super-efficiency DEA model constructed makes up for this defect and realizes the complete ranking between DMUs (Andersen et al., 1993). This improved DEA method has become popular in Eco-efficiency evaluation. Fu et al. (2013) used super-efficiency DEA model to calculate the Eco-efficiency of an urban agglomeration, and analyzed the spatial and temporal evolution trend of efficiency value, and used Tobit regression method to analyze the key factors affecting Eco-efficiency. Zhao \& Huang (2019) used super-efficiency DEA method to calculate the static efficiency of scientific research and development efficiency in China, further analyzed the real situation of scientific research and technical efficiency, and put forward some suggestions. However, most traditional super-efficiency models do not consider undesirable outputs. Tone (2001) further developed a super-SBM model, taking into account undesirable outputs.

DEA method is used to calculate the efficiency value of a time point. It is a method to calculate the static efficiency, which is not conducive to the comparison from the time dimension. When the data form of the decision-making unit is panel data, in order to further study the spatio-temporal evolution trend of the efficiency of the evaluation object, the Malmquist index model is needed for analysis, which is proposed by Malmquist (1953), and then combined with DEA model by Färe et al.(1992), and gradually developed into a method that can be used to analyze the dynamic efficiency of decision objects. Guo (2015) used this method to calculate the total factor productivity of China 's industrial sector. Zhang et al.(2021) calculated the carbon unlocking efficiency of the Yangtze River Economic Belt based on the Malmquist index model. However, the existing research mostly adopts the Malmquist index model based on the CRS hypothesis of Färe et al.(1994), which cannot reflect the real changes of DMU. In order to solve this problem, Ray et al.(1997) considered the Malmquist index method based on VRS, and the $\Delta$ Tech decomposed by this method reflects the real change of decision objects. This paper will adopt the Malmquist index model based on the VRS assumption, which is more suitable for evaluating dynamic changes of Eco-efficiency.

\section{Study on Influencing Factors of Eco-efficiency}

DEA method and Malmquist index model measure the efficiency of DMU, these two methods can not get the key factors affecting the decision object. Therefore, in order to put forward guiding suggestions and opinions on the DMU more targeted, it is necessary to adopt an effective analysis method of influencing factors.

Common analysis methods include Factor Analysis Approach (Liu \& Zhao,2015), Least Square Method (Yu \& Liu, 2015), Stochastic Frontier Approach (Chen 2014) and so on.
However, the efficiency value calculated by DEA method has a lower limit, and the Tobit regression method is more suitable for the analysis of influencing factors. Research on the influencing factors of efficiency, Tobit regression method is also commonly used, such as Ye (2021), Sun et al. (2021) and Yuan et al.(2021) using Tobit method to analyze the factors affecting efficiency.

With the further study of influencing factors and driving mechanism, the mathematical model, research methods and research objects are more diversified. For example, Chen (2008) made an empirical analysis of China 's Eco-efficiency evaluation and influencing factors using provincial data from 2000 to 2006. Based on the SBM-Malmquist-Tobit model, Bai et al. (2013) analyzed the environmental efficiency differences and influencing factors of nine provinces (regions) along the Yellow River in China. Han et al. (2018) used the SBM model considering unexpected output to measure the Eco-efficiency of the Bohai Rim economic circle, and used panel data and regression models to analyze its influencing factors.

At present, many factors affecting Eco-efficiency have been verified by scholars at different levels. Wu \& Ma (2016) showed that per capita GDP and geographical location east of the region have a positive impact on Eco-efficiency, while industrial structure and population density have a negative impact. Chen (2008) took the evaluation value of regional ecological efficiency as the dependent variable and used the linear regression model to analyze the impact of environmental protection investment, environmental policy and industrial structure on ecological efficiency. The research conclusion shows that environmental protection investment and industrial structure adjustment have positive impacts on the improvement of ecological efficiency.

\section{Summary and Innovation}

The traditional research on Eco-efficiency is mainly based on the ratio of the total amount of the economy to the environmental carrying capacity, and no research on Eco-efficiency based on the perspective of high-quality development has been retrieved in SCI or SSCI. When defining the connotation of ecological efficiency, this paper regards the five dimensions of 'high quality development' as the core output index of' 'ecological efficiency', and expands the connotation of 'Eco-efficiency' to adapt to China's national conditions. Improving ecological efficiency is an important theme of China 's economic and social development. The current research mainly focuses on theoretical and qualitative research, and quantitative empirical research is scarce. Therefore, no matter in the research methods, research objects, can be more depth and breadth of inquiry.

In addition, Zhejiang Province is China's richest province, which has the most active private economy and a diversified economic industry. The Chinese government has proposed the goal of building Zhejiang into a demonstration area of common 
prosperity and a model area that can be replicated nationwide in the future. Therefore, by studying the ecological efficiency of Zhejiang Province and analyzing its high-quality development model, it has demonstration significance for the improvement of ecological efficiency in other provinces.

From the perspective of Eco-efficiency model system, The traditional DEA method is widely used in Eco-efficiency evaluation, but there are some defects. Super-efficiency DEA model makes up for the defects of traditional DEA method, and realizes the complete sorting between DMU. However, the existing super efficiency models are mostly based on the assumption of constant returns to scale (CRS) and do not consider undesirable outputs. In addition, the efficiency measured by the DEA method can be used for horizontal comparison among provinces and cities, which is not conducive to comparison from the time dimension. When the data form of the DMU is panel data, in order to further study the spatio-temporal evolution trend of the efficiency of the evaluation object, the Malmquist index model is needed for analysis.

In order to put forward suggestions on decision-making objects more pertinently, it is necessary to adopt an effective analysis method of influencing factors. This paper establishes the super-SBM model and Malmquist index model of unexpected output under the assumption of variable returns to scale (VRS), and uses panel Tobit method to analyze the key factors affecting the Eco-efficiency of Zhejiang Province. This study can fill the gaps in research methods and research objects to some extent.

In summary, no matter from the connotation of Eco-efficiency expansion, Eco-efficiency evaluation system can be more in-depth exploration.

\section{Eco-efficiency Model}

\section{Super-SBM Model}

\section{( 1 ) SBM Model}

The traditional DEA model ignores the measurement error caused by variable relaxation and radial problems, so the measurement results are inaccurate. To improve this problem, Tone (2002) proposed a non-radial and nondirective SBM model based on slack variables. Considering that there are undesirable output indicators such as solid waste emissions, waste gas emissions and waste water emissions in the input-output system of Eco-efficiency, the SBM model that can deal with undesirable output is established. The specific model is as follows :

$$
\begin{aligned}
& \beta=\min \frac{1-(1 / m) \sum_{i=1}^{m}\left(s_{i}^{-} / x_{i k}\right)}{1+1 /\left(s_{1}+s_{2}\right)\left(\sum_{j=1}^{s_{1}} s_{j}^{d} / y_{j k}^{d}+\sum_{q=1}^{s_{2}} s_{q}^{u d} / y_{q k}^{u d}\right)} \\
& \text { s.t. } x_{i k}=\sum_{r=1}^{n} x_{i r} \lambda_{r}+s_{i}^{-}, i=1,2, \mathrm{~L}, m ; \\
& y_{j k}^{d}=\sum_{r=1}^{n} y_{j r} \lambda_{r}-s_{j}^{d}, j=1,2, \mathrm{~L}, s_{1} ; \\
& y_{q k}^{u d}=\sum_{r=1}^{n} y_{q r}^{u d} \lambda_{r}+s_{q}^{u d}, q=1,2, \mathrm{~L}, s_{2} ; \\
& \sum_{r=1}^{n} \lambda_{r}=1 ; \\
& s_{i}^{-}, s_{j}^{d}, s_{q}^{u d}, \lambda_{r} \geq 0, \forall i, j, q, r .
\end{aligned}
$$

where, $n$ : the number of decision-making units. $m$ : Number of inputs. $s_{1}$ and $s_{2}$ : the number of expected and unexpected outputs. $y^{d}$ and $y^{u d}$ : expected and unexpected outputs. $s^{d}$ : insufficient expected output. $s^{-}$and $s^{\text {ud }}$ : excess of input and unexpected output. $\sum_{r=1}^{n} \lambda_{r}=1$ represents the consideration of VRS hypothesis. The scope of the objective function $\beta$ is $[0,1]$, if and only if $\beta=1, s^{-}=s^{d}=s^{u d}=0$, the DMU is valid. If $\beta<1$, the DMU is not valid, so Eco-efficiency need to be improved.

\section{(2) Super-SBM}

Tone proposed a Super-SBM model to evaluate the effective DMUs of SBM, which makes up for the defect that SBM model cannot realize the complete sorting of decision-making units. When super-efficiency SBM is evaluated, it is necessary to use SBM model to identify effective DMUs. When the DMU is SBM effective, Super-efficiency is further used to calculate the efficiency value. The formula (2) is the Super-SBM model considering undesirable outputs.

$$
\begin{aligned}
& \beta^{*}=\min \frac{(1 / m) \sum_{i=1}^{m}\left(\bar{x}_{i} / x_{i k}\right)}{1 /\left(s_{1}+s_{2}\right)\left(\sum_{j=1}^{s_{1}} \bar{y}_{j}^{d} / y_{j k}^{d}+\sum_{q}^{s_{2}} \bar{y}_{q}^{u d} / y_{q k}^{u d}\right)} \\
& \text { s.t. } \bar{x}_{i} \geq \sum_{r=1, r \neq k}^{n} \lambda_{r} x_{i r}, i=1,2, \mathrm{~K}, m ; \\
& \quad \bar{y}_{j}^{d} \leq \sum_{r=1, r \neq k}^{n} \lambda_{r} y_{j r}, j=1,2, \mathrm{~K}, s_{1} ; \\
& \quad \bar{y}_{q}^{u d} \geq \sum_{r=1, r \neq k}^{n} \lambda_{r} y_{q r}, q=1,2, \mathrm{~K}, s_{2} ; \\
& \quad \bar{x}_{i} \geq x_{i k}, i=1,2, \mathrm{~K}, m ; \\
& \bar{y}_{j}^{d} \leq y_{j k}, j=1,2, \mathrm{~K}, s_{1} ; \\
& \bar{y}_{q}^{u d} \geq y_{q k}, q=1,2, \mathrm{~K}, s_{2} ; \\
& \sum_{r=1, r \neq k}^{n} \lambda_{r}=1 ; \lambda_{r}, \bar{y}_{j}^{d} \geq 0, \forall j, r, r \neq k .
\end{aligned}
$$

For the DMUs of SBM effective $\left(\beta=1, s^{-}=s^{d}\right.$ $\left.=s^{u d}=0\right)$, the super-SBM model will recalculate its production frontiers. For the non-effective $(\beta<1)$ DMUs of SBM, 
the production frontiers do not change, and the results are consistent with the SBM model's.

\section{Malmquist Index Model}

Malmquist index was first proposed by Malmquist sten, and then DEA-Malmquist theory was developed, which can better depict the dynamic change of relative efficiency.

Under the technical conditions of period $t$, the change of technical efficiency from period to period $t+1$ is expressed as:

$$
M^{t}=\frac{D^{t}\left(x^{t+1}, y^{t+1}\right)}{D^{t}\left(x^{t}, y^{t}\right)}
$$

Under the technical conditions of period $t+1$, the change of technical efficiency from period t to period $t+1$ is expressed as:

$$
M^{t+1}=\frac{D^{t+1}\left(x^{t+1}, y^{t+1}\right)}{D^{t+1}\left(x^{t}, y^{t}\right)}
$$

Malmquist index uses the geometric mean of formula (33 ) and formula (5) to calculate the change of productivity:

$$
\begin{aligned}
& M\left(x^{t}, y^{t}, x^{t+1}, y^{t+1}\right) \\
& =\left(M^{t} \times M^{t+1}\right)^{\frac{1}{2}} \\
& =\left[\frac{D^{t}\left(x^{t+1}, y^{t+1}\right)}{D^{t}\left(x^{t}, y^{t}\right)} \times \frac{D^{t+1}\left(x^{t+1}, y^{t+1}\right)}{D^{t+1}\left(x^{t}, y^{t}\right)}\right]^{\frac{1}{2}} .
\end{aligned}
$$

Fare et al.(1994) further decomposed the Malmquist index into technical progress index, pure technical efficiency change, and scale efficiency change. Fare studies the Malmquist index model based on the CRS assumption. This paper uses the RD-ML index model of Ray et al. (2007) to measure the Ecoefficiency. Its total factor productivity decomposition formula is:

$$
\begin{aligned}
& M\left(x_{i}^{t}, y_{i}^{t}, x_{i}^{t+1}, y_{i}^{t+1}\right) \\
& =\left[\frac{D_{i}^{t}\left(x_{i}^{t+1}, y_{i}^{t+1}\right)}{D_{i}^{t}\left(x_{i}^{t}, y_{i}^{t}\right)} \times \frac{D_{i}^{t+1}\left(x_{i}^{t+1}, y_{i}^{t+1}\right)}{D_{i}^{t+1}\left(x_{i}^{t}, y_{i}^{t}\right)}\right]^{\frac{1}{2}} \\
& =\left[\frac{D_{i}^{t}\left(x_{i}^{t+1}, y_{i}^{t+1}\right)}{D_{i}^{t+1}\left(x_{i}^{t+1}, y_{i}^{t+1}\right)} \times \frac{D_{i}^{t}\left(x_{i}^{t}, y_{i}^{t}\right)}{D_{i}^{t+1}\left(x_{i}^{t}, y_{i}^{t}\right)}\right]^{\frac{1}{2}} \times \frac{D_{i}^{t+1}\left(x_{i}^{t+1}, y_{i}^{t+1}\right)}{D_{i}^{t}\left(x_{i}^{t}, y_{i}^{t}\right)} \\
& =\left[\frac{D_{i, v}^{t}\left(x_{i}^{t}, y_{i}^{t}\right)}{D_{i, v}^{t+1}\left(x_{i}^{t}, y_{i}^{t}\right)} \times \frac{D_{i, v}^{t}\left(x_{i}^{t+1}, y_{i}^{t+1}\right)}{D_{i, v}^{t+1}\left(x_{i}^{t+1}, y_{i}^{t+1}\right)}\right]^{\frac{1}{2}} \times \frac{D_{i, v}^{t+1}\left(x_{i}^{t+1}, y_{i}^{t+1}\right)}{D_{i, v}^{t}\left(x_{i}^{t}, y_{i}^{t}\right)} \times \\
& {\left[\frac{D_{i, c}^{t}\left(x_{i}^{t+1}, y_{i}^{t+1}\right) / D_{i, v}^{t}\left(x_{i}^{t+1}, y_{i}^{t+1}\right)}{D_{i, c}^{t}\left(x_{i}^{t}, y_{i}^{t}\right) / D_{i, v}^{t}\left(x_{i}^{t}, y_{i}^{t}\right)} \times \frac{D_{i, c}^{t+1}\left(x_{i}^{t+1}, y_{i}^{t+1}\right) / D_{i, v}^{t+1}\left(x_{i}^{t+1}, y_{i}^{t+1}\right)}{D_{i, c}^{t+1}\left(x_{i}^{t}, y_{i}^{t}\right) / D_{i, v}^{t+1}\left(x_{i}^{t}, y_{i}^{t}\right)}\right]^{\frac{1}{2}} .}
\end{aligned}
$$

$$
M\left(x_{i}^{t}, y_{i}^{t}, x_{i}^{t+1}, y_{i}^{t+1}\right)=T E \times E C=T E \times P E C H \times S E C H=T F P .
$$

Among them, $x_{i}^{t}$ and $y_{i}^{t}$ : regional input and output in the year $t_{k} . D_{i}^{t_{k}}\left(x_{i}^{t_{j}}, y_{i}^{t_{j}}\right)$ : Distance function, expressed as the distance between decision unit $i$ in $t_{j}$ and production potential set hyperplane in $t_{k}, v$ : Remuneration for scale changing. $c$ : Fixed-scale remuneration.

$\mathrm{TE}$ is the technological progress index. EC is the change of technical efficiency. PECH is pure technical efficiency. $\mathrm{SECH}$ is scale efficiency. TFP (Tfpch) is total factor productivity. If TFP $>1$, the total factor productivity in the past year has increased. If TFP $<1$, the total factor productivity in the past year has decreased. If $\mathrm{PECH}>1$, pure technical efficiency increased over the past year, If $\mathrm{PECH}<1$, pure technical efficiency decreased over the past year. If $\mathrm{TE}>1$, technological progress has a positive impact on TFP change rate. If $\mathrm{TE}<1$, technological progress has a negative impact on TFP change rate. If $\mathrm{SECH}>1$ indicates that the decision-making unit is further closer to the optimal returns to scale, and $\mathrm{SECH}<1$ indicates that the decision-making unit is further away from the optimal scale reward direction.

\section{Tobit Regression Model}

Tobit regression model, also known as restricted dependent variable model, was first established by Tobin et al.(1958). Guo et al.(2012) and Han et al.(2011) both used the combination of super-efficiency model and Tobit model to analyze the factors affecting efficiency.

Considering that the Eco-efficiency is a value greater than or equal to 0 , the direct regression of the model with the traditional linear method may obtain a negative fitting value. In addition, the efficiency value is a discrete distribution data with lower limit. If the least square method is used, the parameter estimation will have serious deviation. In this paper, Tobit regression model is selected, Tobit proposes maximum likelihood estimation to estimate the model. The specific model (Tobit) is as follows:

$$
\begin{aligned}
& y_{i}^{*}=\beta x_{i}+u_{i} \quad u_{i} \sim N\left(0, \sigma^{2}\right) \\
& \begin{cases}y_{i}=y_{i}^{*} & \text { if } y_{i}^{*}>0, \\
y_{i}=0 & \text { if } \quad y_{i}^{*} \leq 0 .\end{cases}
\end{aligned}
$$

When $y_{i}=0$,

$$
\begin{aligned}
P\left(y_{i}=0 \mid x_{i}\right) & =P\left(y_{i}^{*} \leq 0 \mid x_{i}\right)=P\left(u_{i}<-x_{i}^{\prime} \beta \mid x_{i}\right) \\
& =P\left(u_{i} / \sigma<-x_{i}^{\prime} \beta / \sigma \mid x_{i}\right)=\Phi\left(-x_{i}^{\prime} \beta / \sigma\right) .
\end{aligned}
$$

When $y_{i}>0$,

$$
\begin{aligned}
P\left(y_{i}>0 \mid x_{i}\right) & =P\left(y_{i}^{*}>0 \mid x_{i}\right)=1-P\left(u_{i} \leq-x_{i}^{\prime} \beta \mid x_{i}\right) \\
& =1-P\left(u_{i} / \sigma \leq-x_{i}^{\prime} \beta / \sigma \mid x_{i}\right)=\Phi\left(x_{i}^{\prime} \beta / \sigma\right) .
\end{aligned}
$$

The probability density function is :

$$
f\left(y_{i} \mid x_{i}\right)=\left[\Phi\left(-\frac{x_{i}^{\prime} \beta}{\sigma}\right)\right]^{I_{y_{i}=0}}\left[\frac{1}{\sigma} \phi\left(\frac{y_{i}-x_{i}^{\prime} \beta}{\sigma}\right)\right]^{I_{y_{i}>0}}
$$

where $I$ is an indicator function, and the value is 1 when the conditions expressed by the current standard are correct, otherwise it is 0 . The logarithmic likelihood function is :

$$
\ln L=\sum_{i=1}^{n}\left\{I_{y_{i}=0} \ln \left[\Phi\left(-\frac{x_{i}^{\prime} \beta}{\sigma}\right)\right]+I_{y_{i}>0} \ln \left[\frac{1}{\sigma} \phi\left(\frac{y_{i}-x_{i}^{\prime} \beta}{\sigma}\right)\right]\right\} \text {. }
$$


Finally, the parameters $\beta$ and $\sigma$ are obtained by taking the maximum value $\ln L$.

The hypothesis test of Tobit model is implemented by likelihood ratio test, which assumes that

$$
H_{0}: \beta=\beta_{0}
$$

The test statistics is

$$
L R=-2\left(\ln L_{r}-\ln L_{u}\right) \sim \chi^{2}(j) .
$$

Where $\ln L_{r}$ is the constrained likelihood function value, and $\ln L_{u}$ represents the unconstrained likelihood function value.

\section{Empirical Analysis of 11 Cities in Zhejiang Province}

\section{Reconstruction of the New Connotation of Eco-efficiency: Based on the Perspective of High-quality Development}

Based on the perspective of high-quality development, the definition of Eco-efficiency should not only focus on the perspective of simple ecological environment, but also from multiple perspectives such as capital, economy, science \& technology and social development. Eco-efficiency refers to the ratio of output to input. Input refers to the consumption of urban capital investment, manpower, resources and energy. Eco-efficiency indicators can well represent the quality of a regional development, which is a measure of extensive or intensive regional development comprehensive indicators. This paper regards 'highquality development' as one of the leading indicators of 'Ecoefficiency'. Its output system is not only considered from the total economy, but also from the five dimensions of high-quality development of human society's innovation, coordination, green, sharing and openness'.

\section{Construction of Eco-efficiency Index System}

\section{Indicator System of Input and Output of Eco-efficiency}

On the basis of defining the connotation of Eco-efficiency, the relationships between Eco-efficiency and factors such as resources, environment, capital, human resources, science and technology and economic development are analyzed. According to the correlation and internal regularity of factors, the Ecoefficiency evaluation index system is established. The design of indicators not only follows the principles of systematicness, dynamicness and typical representativeness, but also follows the principles of comparability and quantifiableness. In other words, the calculation and measurement methods of indicators selection among provinces must be consistent and have strong micro-level, which can be collected in authoritative data sources. The Eco-efficiency input index includes basic input, resource input and capital input. Output indicators include innovation, coordination, green, open, sharing and other five indicators. The details are shown in Table 1.

Larger ecological input will produce larger output. Since the greater the basic input is, the greater the pressure on the environment is, the basic input needs to include the most basic production factors : the employment population and land resources. Due to the limited overall resources, the consumption of traditional energy has a certain impact on the ecological environment, so the input index should include the module of resource consumption. In addition, capital investment should be fully considered in social production.

The output of human society has many forms. Based on the perspective of high-quality development, the output system of Eco-efficiency is not only considered from the total economy, but also from the five aspects of the key ' innovation, coordination, green, sharing and opening ' of high-quality development of human society. Each aspect selects some representative indicators. Ten thousand patent licensing index is an intuitive indicator of regional innovation capability.

The opening level is reflected by import and export proportion index. Sharing is characterized by residents ' disposable income indicators. The three waste emissions in nongreen output include three indicators (wastewater, waste gas and solid waste). In terms of coordination, the regional Theil index is defined according to the Theil entropy to measure the disposable income gap between urban and rural areas. It is an important indicator to measure the level of regional coordination, which belongs to the cost-based index. The smaller the index value is, the better the coordination degree is. Its calculation formula :

$$
T(m, t)=\sum_{i=1}^{2}\left(\frac{D I_{i}(m, t)}{D I(m, t)}\right) \ln \left(\frac{D I_{i}(m, t) / D I(m, t)}{P_{i}(m, t) / P(m, t)}\right) .
$$

Among them, $T(m, t)$ : the theil index of region $\mathrm{m}$ in the year $t ; D I_{i}(m, t)$ and $P_{i}(m, t)$ represent urban/ rural disposable income and population ( $i=1$ is urban, $i=2$ is rural) of the region $\mathrm{m}$ in the year $t$ respectively; $D I(m, t)$ and $P(m, t)$ represent the total income and total population of the region $\mathrm{m}$ in the year $t$. In addition, the coordinated output is the expected output, but the regional Theil index is a cost-based indicator, so the regional Theil index is processed according to the unexpected output in the empirical analysis.

In order to make the research more scientific, it is required that all representative indicators can be obtained from the government date source. The evaluation index data in this paper are all from the statistical yearbooks and statistical bulletins of "Statistical Yearbook of Zhejiang Province", "Statistical Yearbook of Science and Technology of Zhejiang Province", "Statistical Yearbook on Environment and Resources of Zhejiang Province". Due to the differences in statistical calibers, some data are missing in a few years, so it is necessary to select the 
appropriate interpolation model through mathematical interpo-

lation method for processing.

Table 1 Input and Output Indexes of Eco-efficiency

\begin{tabular}{cccc}
\hline Primary indicators & Secondary indicators & Tertiary indicators & Unit \\
\hline \multirow{3}{*}{ Input indicators } & Basic input & Quantity of employment & Million people \\
& Energy input & Land area & Square kilometer \\
& Capital input & Energy consumption & Million tons \\
& Innovation & Total financial expenditure & Billion dollar \\
\cline { 2 - 4 } & Coordination & Universal patent index & $\%$ \\
\cline { 2 - 4 } Output indicator & Open & Theil index & $\%$ \\
\cline { 2 - 4 } & Sharing & Residents' disposable income & Million dollar \\
\cline { 2 - 4 } & \multirow{2}{*}{ Unexpected output } & Industrial waste water emissions & Million tons \\
\cline { 2 - 4 } & & Industrial waste gas emissions & Million tons \\
\cline { 2 - 4 } & & Industrial solid waste production & Million Tons \\
\hline
\end{tabular}

(2) Factors Influencing Eco-efficiency

By study on the relevant literatures, the main factors affecting the eco-efficiency based on the perspective of high-quality development can be considered from the following five aspects: industrial structure, economic development level, urbanization level, scientific research level and export trade.

Firstly, a reasonable industrial structure is not only conducive to economic and social development, but also can promote the improvement of people's material and cultural life. This paper selects the proportion of the tertiary industry to measure the industrial structure.

Secondly, economic development is the fundamental force to drive the high-quality development and one of the most important indicators affecting the output of Eco-efficiency (Huang \& Wang, 2015). This paper selects per capita GDP to measure economic level.

Furthermore, urbanization level is conducive to promoting the development of the city to a certain extent, but excessive urbanization may cause excessive urban load. Therefore, the level of urbanization may affect the Eco-efficiency. This paper selects urbanization rate to measure urbanization level.

In addition, innovation is not only the first driving force for high-quality development, but also an important driving force for improving ecological efficiency, and innovation is mainly due to the improvement of science and technology. This paper selects R \& D per million population to measure the level of scientific research.

Finally, import and export will promote higher levels of openness, thereby enhancing ecological efficiency and promoting high-quality regional development. Foreign trade has also played an important role in promoting growth, expanding employment and improving people 's living standards. This paper selects the proportion of import and export to measure export trade.

Based on the above analysis, this paper takes Eco-efficiency as the explained variable, and industrial structure, economic development level, urbanization level, scientific research level and export trade as explanatory variables, as shown in Table 2.

Table 2 Variables that influence Eco-efficiency

\begin{tabular}{|c|c|c|c|}
\hline $\begin{array}{c}\text { Variable being ex- } \\
\text { plained }\end{array}$ & Explanatory variables & Variable indexes & Indicator description \\
\hline \multirow{5}{*}{ Eco-efficiency } & Industrialization structure & Proportion of the tertiary industry & $\begin{array}{l}\text { Gross GDP of third industry } \\
\text { / GDP }\end{array}$ \\
\hline & Economic development level & Per capita GDP & GDP / total population \\
\hline & Urbanization level & Urbanization rate & $\begin{array}{l}\text { Urban population / } \\
\text { total population }\end{array}$ \\
\hline & Scientific research level & R\&D per ten thousand population & $\begin{array}{l}10000 * \mathrm{R} \& \mathrm{D} / \\
\text { total population }\end{array}$ \\
\hline & Export trade & Proportion of imports and exports & Total import and export value / GDP \\
\hline
\end{tabular}




\section{Eco-efficiency Analysis: Based on Super- SBM Model}

The number of DMUs should be more than the product of the number of input and output indicators, and not less than three times the number of input and output indicators (Cooper et al., 2007), namely

$$
n \geq \max \{s \times m, 3(s+m)\} .
$$

In order to compare horizontally and vertically at a unified scale, each city of 11 cities in Zhejiang Province from 2009 to 2018 is taken as a DMU, and a total of 110 DMUs are combined. Overall, the DMUs of 11 cities selected in this paper meets the requirements of formula (15).

Using the SBM model and SBM model of unexpected output super-efficiency under the VRS assumption, the Eco-efficiency of 11 cities in Zhejiang Province from 2009 to 2018 is calculated by Matlab programming, and the results are shown in Table 3. In addition to using the SBM model, it is necessary to use SBM model to identify effective DMUs. For those DMUs with efficiency evaluation value of 1, Super-SBM model will recalculate their production frontiers. For those DMUs with efficiency value less than 1 , the production frontiers does not change, and the results of Super-SBM are consistent with those of the SBM model.

Table 3 Eco-Efficiency of 11 Cities in Zhejiang Province

\begin{tabular}{cccccccccccc}
\hline \multicolumn{2}{c}{ Area } & \multicolumn{10}{c}{ Year } \\
\cline { 3 - 12 } \multicolumn{2}{c}{} & $\mathbf{2 0 0 9}$ & $\mathbf{2 0 1 0}$ & $\mathbf{2 0 1 1}$ & $\mathbf{2 0 1 2}$ & $\mathbf{2 0 1 3}$ & $\mathbf{2 0 1 4}$ & $\mathbf{2 0 1 5}$ & $\mathbf{2 0 1 6}$ & $\mathbf{2 0 1 7}$ & $\mathbf{2 0 1 8}$ \\
\hline Northern & Hangzhou & 0.316 & 0.379 & 0.494 & 0.558 & 0.546 & 0.576 & 0.741 & 1.006 & 1.029 & 1.050 \\
Zhejiang & Jiaxing & 0.278 & 0.327 & 0.372 & 0.385 & 0.411 & 0.448 & 0.501 & 0.582 & 0.574 & 1.046 \\
& Huzhou & 0.287 & 0.29 & 0.371 & 0.398 & 0.376 & 0.461 & 1.006 & 1.029 & 0.72 & 1.023 \\
Eastern & Ningbo & 1.005 & 1.001 & 1.008 & 1.024 & 1.001 & 1.005 & 1.027 & 0.859 & 0.915 & 1.056 \\
Zhejiang & Zhoushan & 1.000 & 1.000 & 1.000 & 1.043 & 1.067 & 1.000 & 1.041 & 1.010 & 1.010 & 1.107 \\
& Shaoxing & 0.344 & 0.379 & 0.453 & 0.412 & 0.411 & 0.417 & 1.002 & 0.612 & 0.560 & 1.030 \\
Southern & Wenzhou & 0.197 & 0.211 & 0.216 & 0.261 & 0.271 & 0.285 & 0.310 & 0.331 & 0.456 & 1.051 \\
Zhejiang & Taizhou & 0.251 & 0.29 & 0.305 & 0.338 & 0.325 & 0.357 & 0.402 & 0.408 & 0.384 & 0.712 \\
& Lishui & 0.185 & 0.206 & 0.225 & 0.227 & 0.232 & 0.236 & 0.255 & 0.254 & 0.250 & 0.355 \\
Western & Jinhua & 0.218 & 0.226 & 0.259 & 0.311 & 0.456 & 0.637 & 1.006 & 0.782 & 0.814 & 1.052 \\
Zhejiang & Quzhou & 0.217 & 0.232 & 0.234 & 0.259 & 0.252 & 0.263 & 0.269 & 0.255 & 0.278 & 0.296 \\
\hline
\end{tabular}

From the perspective of time evolution trend, the overall Eco-efficiency of 11 cities in Zhejiang Province has risen steadily. It is worth noting that the Eco-efficiency of Hangzhou, Huzhou and Jinhua has improved significantly. Except occupying an important geographical advantage, Hangzhou has made a breakthrough in the integrated circuit industry in recent years. With the development of the Internet economy and the acceleration of $5 \mathrm{G}$ commercialization and industrialization, Hangzhou has achieved rapid economic development. The urbanization and development of Hangzhou have entered a relatively mature period, and the indicators are relatively balanced, which ensures the gradual improvement of Eco-efficiency and ranks third in the province in 2018. Hangzhou 's efficiency is slightly lower than Zhoushan and Ningbo, mainly because the vast majority of investment in Hangzhou ranks first in the province, and the output of green undesirable output is too large, the regional Theil index has not yet developed to the optimal, resulting in Eco-efficiency value failed to top. Because Huzhou is close to Hangzhou, driven by Hangzhou ' s economy, Huzhou ' s output indicators have varying degrees of growth, thus achieving steady improvement of Eco-efficiency.

From the spatial dimension, the Eco-efficiency values of each city are quite different. The Eco-efficiency values of Zhoushan and Ningbo have been at a high level, and the Ecoefficiency values of Taizhou and Wenzhou have been at a low level. Within the 11 cities, Zhoushan ' s Eco-efficiency has been higher than others. The reason is that the total amount of various indicators in Zhoushan is far less than that in other leading cities of ecological efficiency, and the low input is the fundamental reason for the high efficiency value. Secondly, Zhoushan, as a coastal city, has a natural advantage in the ecological environment. Ningbo, the earliest pilot area of China's opening to the outside world, which has the highest innovation and sharing indicators, ranked second in Eco-efficiency in 2018 The ecological efficiency of Quzhou and Lishui are located in the reciprocal first and second of 11 cities, respectively. The low input-output ratio is the main reason for the low ecological efficiency. The input of resources, energy and capital in the two places has not significantly promoted scientific, technological \& economic development.

Eco-efficiency is not only different in temporal and spatial dimensions, but also varies in the overall distribution. Figure 1 reflects the overall distribution of Eco-efficiency in 11 cities of Zhejiang Province from 2009 to 2018. 


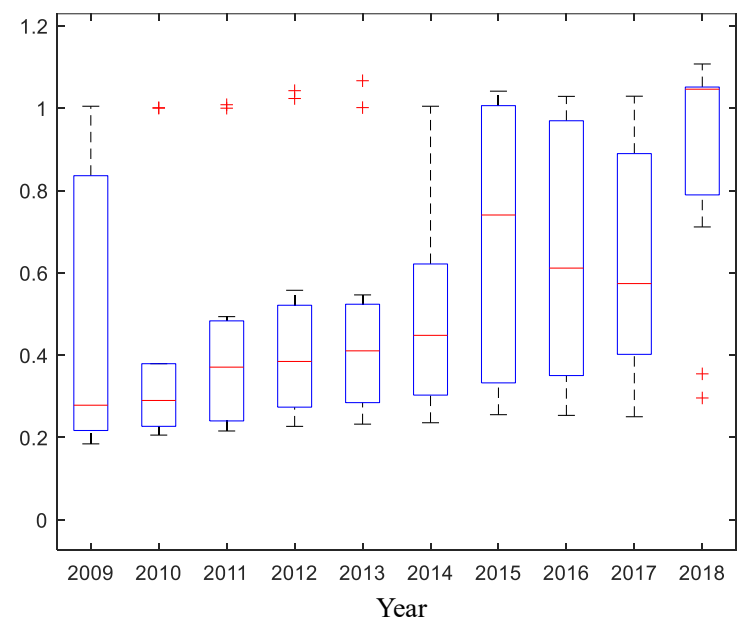

Figure 1 ecological development super efficiency box of 11 cities in Zhejiang Province

As shown in the figure, the lower limit of the Eco-efficiency value in each year was about 0.2 and was relatively stable. Except for 2010-2013, the upper limit of Eco-efficiency value in each year was above 1 . From the median position, the medians of Eco-efficiency values for each year were close to the lower quantile except for 2009, 2015 and 2018, with about 50 per cent of the sample Eco-efficiency values ranging from 0.3 to 0.6 . From the box width, the box width was significantly larger in 2009 and 2014-2017, indicating that the efficiency distribution was relatively discrete. In addition, the figure shows that there were abnormal data from 2010 to 2013 and 2018. In a set of data, the emergence of abnormal values is worthy of attention. Analyzing the causes is likely to make abnormal values an opportunity to find problems and improve decision-making.

\section{Total Factor Decomposition of Eco-efficiency}

DEAP software is used to measure the dynamic efficiency of
Eco-efficiency of 11 cities in Zhejiang Province from 2009 to 2018 using the Malmquist index model under the VRS assumption. Total factor productivity and its decomposition of Ecoefficiency in Zhejiang Province from 2009 to 2018 are shown in table 4.

According to the results shown in Table 4, the Malmquist index of Eco-efficiency in Zhejiang Province showed a trend of first decline and then rise. Total factor productivity was the highest in 2011-2012 and the lowest in 2015-2016. From the perspective of total factor decomposition, the technical progress index in 2011-2012 is the highest, and the technical progress index in 2015-2016 is the lowest. It shows that the technical progress index is consistent with the change of total factor productivity. The total factor productivity of Eco-efficiency in Zhejiang Province has benefited from technical progress over the years. In recent years, technical improvement has played a positive role in improving the Eco-efficiency of Zhejiang Province, and there is still considerable room for improvement in technical efficiency.

Table 4 TFP of Eco-efficiency in ZJ province and its decomposition from 2009-2018

\begin{tabular}{cccccc}
\hline Year & EC & TECH & PECH & SECH & TFP \\
\hline $2009-2010$ & 1.024 & 1.091 & 1.021 & 1.003 & 1.117 \\
$2010-2011$ & 0.943 & 1.143 & 0.973 & 0.969 & 1.078 \\
$2011-2012$ & 1.008 & 1.171 & 0.991 & 1.017 & 1.18 \\
$2012-2013$ & 0.994 & 0.981 & 1.001 & 0.993 & 0.975 \\
$2013-2014$ & 1.028 & 0.996 & 1.026 & 1.002 & 1.024 \\
$2014-2015$ & 0.976 & 1.103 & 0.972 & 1.004 & 1.076 \\
$2015-2016$ & 0.992 & 0.972 & 0.980 & 1.012 & 0.964 \\
$2016-2017$ & 1.031 & 0.976 & 1.014 & 1.017 & 1.006 \\
$2017-2018$ & 1.011 & 1.09 & 1.013 & 0.998 & 1.102 \\
\hline mean value & 0.985 & 1.069 & 1 & 0.985 & 1.053 \\
\hline
\end{tabular}


can be decomposed into pure technical efficiency and scale efficiency), the scale efficiency has gradually improved from 2012 to 2017, the scale efficiency has been less than 1 from 2017 to 2018 , and the pure technical efficiency has been improve 0.035 from 2014 to 2018 . It shows that the improvement of technical efficiency from 2014 to 2018 relies on scale efficiency to provide power in the early stage, and the power of scale efficiency is insufficient to rely on pure technical efficiency in the later stage. Therefore, improving technical efficiency needs to take into account scale efficiency and pure technical efficiency.

Figure 2 reflects the distribution of Malmquist index of Eco-efficiency in 11 cities of Zhejiang Province from 2009 to 2018 .It shows that the Malmquist index of each city is oscillating, and the change law of each city is inconsistent. The Malmquist index of Lishui was the largest in 2009, and then decreased. The Malmquist index of Quzhou City reached its peak in 2012, and the overall trend was stable.Overall, the Malmquist index over the years is mainly concentrated in the range of 0.9-1.2. Jiaxing shows a U-shaped curve, indicating that total factor productivity has shown an increasing trend in recent years, and the mid-year performance from 2009 to 2018 is relatively mediocre.The ML index of other cities fluctuated in general.ML index of Jiaxing/Shaoxing are located above/below other cities in many years, which shows the elasticity of ecological efficiency growth in Jiaxing is greater than that in Shaoxing.

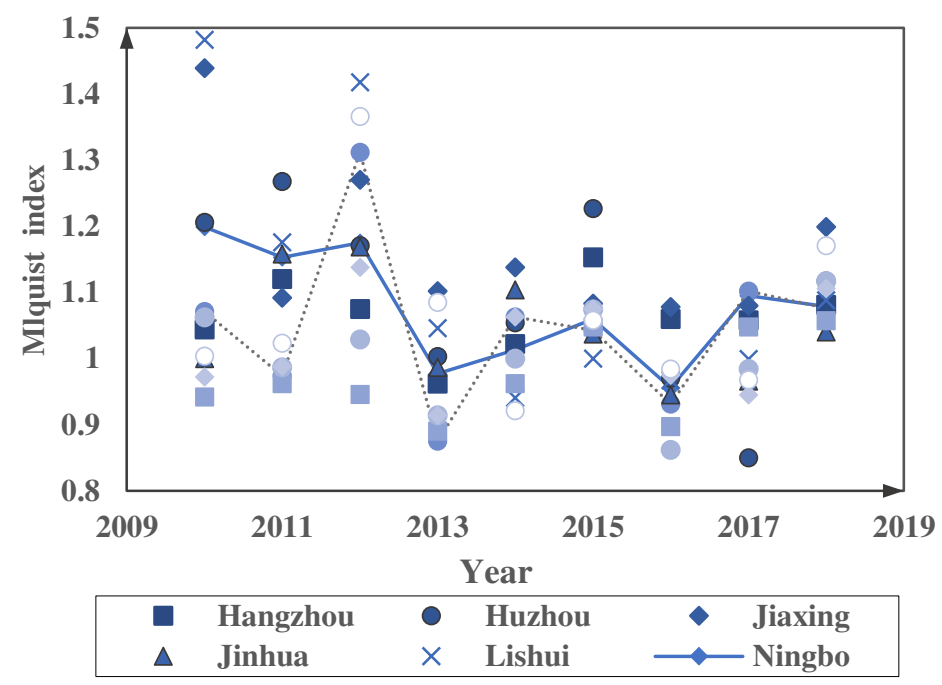

Figure 2 Distribution of Malmquist index of Eco-efficiency in 11 cities of Zhejiang Province

In order to further explore the causes of the change of Malmquist index of Eco-efficiency in each city, the decomposition of total factor productivity of Eco-efficiency in table 5 helps to further grasp the change law of Eco-efficiency in spatial dimension.

Table 5 Total Factor Productivity and Its Decomposition of Eco-efficiency

\begin{tabular}{|c|c|c|c|c|c|c|}
\hline \multicolumn{2}{|c|}{ Area } & \multirow{2}{*}{$\begin{array}{c}\mathrm{EC} \\
0.933\end{array}$} & \multirow{2}{*}{$\begin{array}{c}\text { TECH } \\
1.131\end{array}$} & \multirow{2}{*}{$\frac{\text { PECH }}{1}$} & \multirow{2}{*}{$\begin{array}{c}\text { SECH } \\
0.933\end{array}$} & \multirow{2}{*}{$\begin{array}{c}\text { TFP } \\
1.055\end{array}$} \\
\hline Northern & Hangzhou & & & & & \\
\hline \multirow[t]{2}{*}{ Zhejiang } & Jiaxing & 0.987 & 1.159 & 1 & 0.987 & 1.144 \\
\hline & Huzhou & 1 & 1.115 & 1 & 1 & 1.115 \\
\hline Eastern & Ningbo & 1 & 1.076 & 1 & 1 & 1.076 \\
\hline \multirow[t]{2}{*}{ Zhejiang } & Zhoushan & 1 & 1.081 & 1 & 1 & 1.081 \\
\hline & Shaoxing & 0.966 & 0.969 & 1 & 0.966 & 0.936 \\
\hline Southern & Wenzhou & 0.962 & 1.027 & 1 & 0.962 & 0.988 \\
\hline \multirow[t]{2}{*}{ Zhejiang } & Taizhou & 0.966 & 1.002 & 1.038 & 0.931 & 0.968 \\
\hline & Lishui & 0.978 & 1.154 & 0.956 & 1.023 & 1.129 \\
\hline Western & Jinhua & 1.055 & 1.034 & 1.02 & 1.034 & 1.091 \\
\hline \multirow[t]{2}{*}{ Zhejiang } & Quzhou & 0.996 & 1.031 & 0.993 & 1.003 & 1.027 \\
\hline & mean value & 0.933 & 1.131 & 1 & 0.933 & 1.055 \\
\hline
\end{tabular}

From the perspective of total factor productivity (which can be decomposed into technological progress and technical efficiency), the total factor productivity of Shaoxing, Taizhou and Wenzhou is less than 1, and that of other cities is greater than 1. The technological progress is greater than 1 except Shaoxing, while the technical efficiency fluctuates around 1. g It shows that technological progress is the main source of total factor productivity change. From the perspective of technical efficiency, except Jinhua City, the technical efficiency index of other cities (which can be decomposed into scale efficiency and pure technical efficiency) is not more than 1, mainly due to the decline of scale efficiency, followed by pure technical efficiency less than 1 , of which scale efficiency decline accounted for $45.4 \%$, pure technical efficiency decline accounted for $25 \%$.

Technical efficiency index reflects the advantages and disadvantages of management methods and management structure, and whether the decision-making is correct or not, and technological progress index reflects the progress of technology in the process of Eco-efficiency development. It can be concluded that in recent years, except Shaoxing, other cities have made varying degrees of progress in technology applications. In terms of management and policy formulation, cities still have a 
lot of room for improvement, and mainly reflected in the lack of scale efficiency.

\section{Analysis of Influencing Factors of Eco-efficiency (Panel To- bit Regression Analysis)}

Based on the panel data of 11 cities in Zhejiang Province from 2009 to 2018, the panel Tobit model is used for regression analysis. The regression results are shown in table 4-6. Considering that the Tobit model with unconditional fixed effect is biased, this paper adopts the panel Tobit model with random effect.

The Tobit model regression results in Table 4-5 shows that the chi-square statistic of ecological efficiency in Zhejiang
Province is 157.09 , and it is significant at $1 \%$ level, indicating that the five variables has high explanatory power for the explained variables. Among them, the industrial structure, economic level and export trade are significantly positively correlated with Eco-efficiency. Urbanization level is significantly negatively correlated with Eco-efficiency. There is a positive correlation between scientific research level and Eco-efficiency, but it is not significant.

The regression coefficient of industrial structure on Ecoefficiency of 11 cities in Zhejiang Province is 3.96 E-06, and it is significant at $5 \%$ level. It shows that the proportion of tertiary industry can stimulate regional development and improve its Eco-efficiency.

Table 6 Tobit model regression results

\begin{tabular}{ccccc}
\hline explaining variable & coefficient & standard deviation & z value & $\mathrm{p}$ value \\
\hline Industrial structure & $3.96 \mathrm{E}-06$ & $1.20 \mathrm{E}-06$ & $3.29^{* *}$ & 0.001 \\
economic level & 0.0217524 & 0.0054772 & $3.97^{* * *}$ & 0.000 \\
urbanization level & -0.0123082 & 0.0064593 & $-1.91^{*}$ & 0.057 \\
research quality & 0.0030767 & 0.0022304 & 0.38 & 0.168 \\
foreign trade dependence & 0.0051909 & 0.001058 & -1.49 & 0.000 \\
cons & -0.393292 & 0.2635297 & 0.036 \\
\hline LR chi2(5) $=157.09$ & Prob $>$ chi2 $=0.000$ & & &
\end{tabular}

LR $\operatorname{chi} 2(5)=157.09 \quad$ Prob $>$ chi2 $=0.000$

Note: $* * * * *$ and $*$ represent significant levels of $1 \%, 5 \%$ and $10 \%$ respectively

The regression coefficient of economic level on Eco-efficiency of 11 cities in Zhejiang Province is 0.0217 , and it is significant at $1 \%$ level. It shows that there is a significant positive correlation between per capita GDP and Eco-efficiency. From the previous section of the city 's Eco-efficiency results, the economically developed cities in Zhejiang Province did show a high Eco-efficiency value, such as Hangzhou, Ningbo, etc., and the Eco-efficiency value of some areas with backward economic level is relatively low.

The regression coefficient of urbanization level on the Eco-efficiency of 11 cities in Zhejiang Province is -0.012, and it is significant at the level of $10 \%$. It shows that there is a negative correlation between the level of urbanization and ecological efficiency. Urbanization construction is conducive to the promotion of regional development to a certain extent, but excessive and rapid urbanization may cause excessive load on the city, which is reflected in: urbanization is too fast, the city is too large, and too many people are concentrated in the city in a short time Inevitably, a large number of unemployment, shortage of fresh water and energy supply, environmental degradation and so on will inevitably occur, which hinders the improvement of urban Eco-efficiency to a certain extent.

The regression coefficient of scientific research and technological level on the Eco-efficiency of 11 cities in Zhejiang Province is 0.0031 , but it has not passed the significance test $(\mathrm{P}=0.168)$. However, analyze the relationship between scientific research level and Eco-efficiency, the improvement of the level of scientific research is conducive to the transformation of the economic structure, promoting economic development, and has a huge role in promoting the Eco-efficiency of the city, which is consistent with the expected hypothesis.

The regression coefficient of foreign export trade on the Eco-efficiency of the 11 cities in Zhejiang Province is 0.0051 , which is significant at the $1 \%$ level. To a certain extent, foreign export trade reflects the opening level of the city. The higher the proportion of total import and export value, the more obvious the advantage of foreign export trade. The improvement of import and export advantages will help promote a higher level of opening up, and thus promote the improvement of urban Eco-efficiency.

\section{Summary}

This paper establishes the undesired output super-SBM model and the Malmquist index model under the assumption of VRS, and calculates the Eco-efficiency. In order to further study the key factors affecting the ecological efficiency of Zhejiang Province, the panel Tobit method is used for regression analysis. The results show that the overall ecological efficiency of Zhejiang Province has risen steadily, and the efficiency values of each city are quite different. Among them, the efficiency values of East Zhejiang and North Zhejiang have been at a relatively high level, and the efficiency value of Southern Zhejiang has been at a low level. From the decomposition of the ML index, technological progress is the main source of Eco- 
efficiency improvement, and there is still considerable improvement in technical efficiency in most regions. With the exception of Shaoxing, other cities have achieved different degrees of progress in the application of technology; and in terms of management and policy formulation, there is still a lot of room for improvement in each city, which is mainly reflected in the lack of scale efficiency. From the perspective of Tobit regression analysis, industrialization structure, economic level, and foreign export trade are significantly positively correlated with ecological efficiency; urbanization level is significantly negatively correlated with ecological efficiency; scientific research level is positively correlated with ecological efficiency, but not significant .

Author Contribution $\mathrm{Xu} \mathrm{Xu}$ (frst author): formulation and evaluation of overarching research goals and aims; application of statistical, computational, and other formal techniques to analyze; preparation (drafting, reviewing, translating, and revising the paper), and presentation of the manuscript. Li-zhen Huang (corresponding author): formulation and evaluation of overarching research goals and aims; statistical analysis; preparation (drafting, reviewing, translating, and revising the paper), and presentation of the manuscript. All the authors have read and approved the fnal manuscript.

Funding We would like to acknowledge the support of a Zhejiang Soft Science Research Grant (Project 2020C35014), and the support of a Zhejiang educational reform Grant (Project 2020.1.1) in china.

Data Availability The datasets analyzed during the current study are available from the corresponding author on reasonable request.

Code Availability Not applicable.

\section{Declarations Ethics}

Competing Interests The authors declare no competing interests.

\section{References}

[1] Fare, R., Grosskopf, S., Lovell, C.A.K., et al. (1989) Multilateral Productivity Comparisons When Some Outputs are Undesirable: A Nonparametric Approach. The Review of Economics and Statistics, 71(1), 90-98.

[2] Schaltegger, S., and Sturm, A. (1990). Okologische rationalitat: ansatzpunkte zur ausgestaltung Yonokologieorienttierten management instrumenten. Die Unternehmung, 4, 273-290

[3] Rashidi, K., and Saen, R.F. (2015). Measuring eco-effciency based on green indicators and potentials in energy saving and undesirable output abatement. Energy Econ., 50, 18-26.

[4] Gómez-Calvet, R., Conesa, D., Gómez-Calvet, A.R., and TortosaAus, E. (2016). On the dynamics of eco-efficiency performance in the European Union. Comput.Oper.Res., 66, 336-350.

[5] Yang, L., and Yang, Y. (2019). Evaluation of eco-efficiency in China from 1978 to 2016: Based on a modified ecological footprint model. Science of the Total Environment, 662, 581-590.

[6] Yang, L., Tang, K., Wang, Z., An, H., and Fang, W. (2017). Regional eco-efficiency and pollutants' marginal abatement costs in China: a parametric approach. J. Clean. Prod., 167, 619-629.

[7] Xing, Z., Wang, J., and Zhang, J. (2018). Expansion of environmental impact assessment for eco-efficiency evaluation of China's economic sectors: an economic input-output based frontier approach. Sci.Total Environ., 635, 284-293.

[8] Zhang, J. (2016). Research on the differences in environmental performance of major urban agglomerations in my country and their causes. Economic System Reform,1, 57-62.

[9] Wu, C., and Huang, L. (2017). Evolution trajectory, performance evaluation and the green development of the city group in the middle reaches of the Yangtze River. Reform, 3, 65-77.

[10] Bi, D., Wang, K., and Wang, L.(2018). Industrial ecological efficiency and its temporal and spatial transition characteristics of the Yangtze River Delta urban agglomeration. Economic Geography, 38(1):167-173.

[11] Basset-Mens, C., Ledgard, S., and Boyes, M. (2009). Eco-effciency of intensification scenarios for milk production in New Zealand. Ecol. Econ., 6, 1615-1625.

[12] Fujii, H., Managi,S. (2013). Determinants of eco-effciency in the Chinese industrial sector[J]. J. Environ., 25, S20-S26.

[13] Xin, Y., and Tao, F. (2019). Optimizing genotype-environmentmanagement interactions to enhance productivity and eco-efficiency for wheat-maize rotation in the North China Plain. Sci. Total Environ, 654, 480-492.

[14] Passetti, E., and Tenucci, A. (2016). Eco-efficiency measurement and the influence of organizational factors: evidence from large Italian companies. J. Clean. Prod., 122, 228-239.

[15] Oliveira,R., Camanho, A.S., and Zanella, A. (2017). Expanded eco-effciency assessment of large mining firms. J. Clean. Prod., 20, 2364-2373.

[16] Huang, H, Wu, S., Zhi, Y., et al. (2010). Dynamic evaluation of resource and environmental performance based on eco-efficiency: Taking Jiangxi Province as an example. Resources Science, 32(5), 924-931.

[17] Yang, L., and Du, P. (2017). Evaluation of urban eco-efficiency based on factor analysis and super-efficiency DEA. Statistics and Decision, 16, 52-55.

[18] Liang, X., and Zhuo, D. (2017). Evaluation of China's regional ecological efficiency and analysis of influencing factors. Statistics and Decision, 19, 143-147.

[19] Gu, P., and Liu, Z. (2017). Evaluation of regional industrial ecoefficiency based on material flow analysis: Taking Hunan Province as an example. Economic Geography, 37(4), 141-148.

[20] Huang, X., and Wang, T. (2015). Ecological efficiency evaluation of resource-based cities. Scientific Research Management, 36(7), 70-78.

[21] Kuosmanen, T., and Kortelainen, M. (2005). Measuring eco-efficiency of production with data envelopment analysis. J. Ind. Ecol., 9, 59-72.

[22] Picazo-Tadeo, A.J., Beltrán-Esteve, M., and Gómez-Limón, J.A. (2012). Assessing eco-efficiency with directional distance functions. Eur. J. Oper. Res., 3, 798-809.

[23] Rebolledo-Leiva, R., Angulo-Meza, L., Iriarte, A., et al. (2017) 
Joint carbon footprint assessment and data envelopment analysis for the reduction of greenhouse gas emissions in agriculture production. Sci. Total Environ., 593, 36-46.

[24] Huang, J., Yang, X., Cheng, G., and Wang, S. (2014). A comprehensive eco-efficiency model and dynamics of regional eco-efficiency in China. Journal of Cleaner Production, 67, 228-238.

[25] Zhang, B., Bi, J., Fan, Z., et al. (2008). Eco-efficiency analysis of industrial system in China: A data envelopment analysis approach. Ecological Economics, 68(1-2), 306-316.

[26] Anderson, T. R., Hollingsworth, K., and Inman, L. (2002). The Fixed Weighting Nature of A Cross-Evaluation Model[J]. Journal of Productivity Analysis, 17(3), 249-255.

[27] Fu, L., Chen, X., and Leng, Z. (2013). Research on the Eco-efficiency of Urban Agglomeration Based on Super-Efficiency DEA Model__ Taking the "3+5" Urban Agglomeration of Changsha, Zhuzhou and Xiangtan as an Example. China Population Resources and Environment, 23(4), 169-175.

[28] Zhao, J., and Huang, S. (2019). Research on the evaluation of China's scientific and technological R\&D efficiency based on superefficiency DEA and Malmquist index. Macroeconomic Research, 09, 123-129.

[29] Tone, K. (2001). A slacks-based measure of efficiency in data envelopment analysis. European Journal of Operational Research, 130(3), 498-509.

[30] Malmquist S. (1953) Index numbers and indifference surfaces. Trabajos De Estadistica, 4(2), 209-242.

[31] Färe, R., Grosskopf, S., LindgrenB, and Roos, P. (1992). Productivity changes in Swedish pharamacies 1980-1989: A non-parametric Malmquist approach. Journal of Productivity Analysis, 3(1-2), 85-101.

[32] Guo, J. (2015). Research on the Decomposition and Influencing Factors of China's Industrial Technology Progress: Malmquist Index Method Based on DEA. Economic Survey, 32(5), 79-84.

[33] Zhang, J., Liu, Q., and Ding, X. (2021). Research on the efficiency of carbon unlocking in the Yangtze River Economic Zone: Based on SE-DEA-Malmquist Index. East China Economic Management, 35(6): 1-10.

[34] Fare, R., Grosskopf, S., Norris, S., and Zhang, Z. (1994). Productivity growth, technical progress, andefficiency change in industrialized countries. American Economic Review, 84(1), 66-83.

[35] Ray, S. C., and Desli E. (1997). Productivity Growth, Technical Progress, and Efficiency Change inIndustrialized Countries: Comment. American Economic Review, 87(5), 1040-1043.

[36] Liu, Z., and Zhao, T. (2015). Contribution of price expenditure factors of residential energy consumption in China from 1993 to 2011: A decomposition analysis. Energy Conversion \& Management, 98, 401-410.

[37] Yu, Y., and Liu, X. (2015). Inter-provincial environmental efficiency evaluation based on SBM-overall model. Statistics and Decision, 4,57-60.

[38] Chen, G. (2014). Research on Total Factor Energy Efficiency and Influencing Factors of China's Manufacturing Industry: A Stochastic Frontier Analysis Based on Panel Data. China Soft Science, 1, 180-192.

[39] Ye, W. (2021). Environmental efficiency analysis of six provinces in central China based on SBM-Tobit model. Journal of Southwest University (Natural Science Edition), 43(3), 139-146.

[40] Sun, Z., Lu, S., and Liu, C. (2021). Research on the evaluation and improvement path of provincial regional ecological effi- ciency: Based on the super-efficiency SBM model and Tobit regression. Ecological Economy, 37(1), 124-129.

[41] Yuan, Y., Zhang, Y., Ma, R., Wang, Y., He, P., and Yu, Q. (2021). Research on the efficiency of knowledge exchange in online health communities based on the SBM-Tobit model. Information Science, 39(5), 106-114.

[42] Chen, A. (2008). Evaluation of Regional Eco-efficiency in China and Empirical Analysis of Influencing Factors, Chinese Management Science, 16(10), 566-570.

[43] Bai, Y., Zhang, X., Hao, Y., et al. (2013). Analysis of environmental efficiency differences and influencing factors of the nine provinces (regions) along the Yellow River based on the SBMMalmquist-Tobit model. Regional Research and Development, 32(002): 90 -95.

[44] Han, Z., Wu, A., and Peng, F. (2018). Ecological efficiency in the Bohai Rim region based on undesired output and threshold regression model. Advances in Geographical Sciences, 37(2),255265.

[45] Wu, M., and Ma, J. (2016). China's regional ecological efficiency measurement and analysis of its influencing factors: based on the DEA-Tobit two-step method. Technoeconomics, 35(03), 75$80+122$.

[46] Chen, A. (2008). China Regional Eco-efficiency Evaluation and Empirical Analysis of Influencing Factors: Taking Inter-provincial Data from 2000 to 2006 as an Example [J]. Chinese Management Science, 16(S1), 566-570.

[47] Zhao, L., Hza, B., Yjza, B., et al. (2020). How does industrial policy affect the eco-efficiency of industrial sector? Evidence from China. Applied Energy, 272.

[48] Tone, K. (2002). A slacks-based measure of super-efficiency in data envelopment analysis. European Journal of Operational Research, 143(1), 32-41.

[49] Fare, R., Grosskopf, S., Norris, M., and Zhang, Z. (1994). Productivity Growth, Technical Progress, and Efficiency Change in Industrialized Countries. American Economic Review, 84(1), 6683.

[50] Tobin, and James. (1958). Estimation of Relationships for Limited Dependent Variables. Econometrica,26(1), 24-36.

[51] Guo, B., and Lu, Y. (2012). Energy-saving and emission-reduction efficiency evaluation of six provinces in central my country and analysis of its influencing factors: based on super-efficiency DEA model and Tobit model. Technoeconomics, 31(12), 58-62+ 76.

[52] Guo, D., Lei, J., Zhang, J., and Peng, B. (2012). Research on the Efficiency and Influencing Factors of National Innovation System: Based on the Analysis of DEA-Tobit Two-Step Method. Journal of Tsinghua University (Philosophy and Social Sciences Edition), 27(02), 142-150+160.

[53] Han, Y., and Liu, X. (2011).Analysis of energy efficiency and energy saving and emission reduction potential of China's iron and steel industry in various regions based on the super-efficiency DEA model. System Science and Mathematics, 31(03), 287-298.

[54] Zhao, X. (2010) The efficiency measurement of bank branches and analysis of influencing factors: An empirical study based on super-efficient DEA and Tobit model[J]. Economic Science, 1, $85-96$.

[55] Shi, B., Shen, K. (2008). China's total factor energy efficiency under market segmentation: an empirical analysis based on the super-efficiency DEA method. World Economy, 9, 49-59. 
[56] Cooper, W. W., Seiford, L. M., and Tone, K. (2007) Data Envelopment Analysis: A Comprehensive Text with Models, Applications, References and DEA-Solver Software. Kluwer Academic Publishers.

[57] Sun, X., Zhang, H., and Wang, G. (2016) Research on the regional carbon emission efficiency based on the super-efficiency SBM model: Taking 17 prefecture-level cities in Shandong Province as examples. Ecological Economy, 32(05), 68-73. 